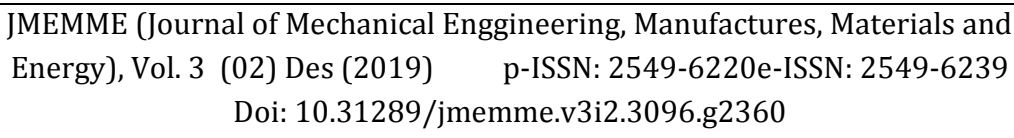

\title{
PENGARUH PENAMBAHAN WATER TUBE DAN PENGGUNAAN AIR PANAS HASIL PENYULINGAN PADA BOILER TERHADAP LAMA WAKTU PENYULINGAN MINYAK PALA
}

\author{
Nuzuli Fitriadi, Yusrizal* \\ Program Studi Teknik Mesin, Politeknik Aceh Selatan \\ Diterima: 15-11-2019 ; Disetujui: 12-12-2019 ; Diterbitkan: 30-12-2019 \\ *Corresponding author: yusrizalmt@gmail.com
}

\begin{abstract}
Abstrak
Kualitas minyak pala ditentukan oleh kualitas pala dan penggunaan teknologi proses pemurnian yang digunakan. Teknik pengeringan untuk bahan baku dan proses penyulingan yang meliputi bahan ketel, sistem pendingin, dan desain ketel untuk penyulingan mempengaruhi hasil dan kualitas minyak atsiri yang dihasilkan. Boiler terbuat dari Stainless steel 304 dengan diameter $70 \mathrm{~cm}$, panjang $120 \mathrm{~cm}$, dan tebal pelat $3 \mathrm{~mm}$. Boiler juga dilengkapi dengan system water tube untuk mempercepat pemanasan air. Tekanan berlebih dikendalikan oleh katup pengaman tekanan karena boiler ini dirancang dengan kapasitas tekanan 3 bar. Ketel terbuat dari Stainless steel 304 yang dilengkapi dengan keranjang bertingkat untuk memaksimalkan sirkulasi dan tekanan uap dalam ketel. Pipa kondensor yang berada dalam air pendingin menggunakan pipa aluminum untuk memaksimalkan proses kondensasi. Selama proses pemanasan air di dalam water tube terus terjadi peningkatan temperatur hingga $80 \mathrm{oC}$ pada menit ke 90 . Temperatur air yang dipompakan ke dalam boiler sudah mencapai 73 oC yang bersumber dari kondensor. Sejalan dengan peningkatan temperatur air di dalam kondensor, hal ini mengakibatkan kestabilan temperatur pada saat penambahan air dalam boiler. Rata-rata penurunan temperatur hanya 2,7 oC. Penggunaan air panas dari kondensor dapat meningkatkan efektifitas boiler untuk menghasilkan uap yang ditransfer ke ketel. Hal ini menyebabkan temperatur di ketel langsung stabil pada menit ke 90 dengan rata-rata temperatur sebesar $110 \mathrm{oC}$. Tempertur air yang dihasilkan oleh kondensor bertahan pada 84-85 oC. Kondisi ini diakibatkan oleh penambahan air ke dalam kondensor yang dilakukan setelah air dalam kondensor tersebut dipompa ke boiler. Tempertur air dalam kondensor ini selain dapat meningkatkan efektifitas boiler dan ketel tetap juga dapt menurunkan kemampuan pipa kondensor untuk merubah fase uap ke cair. Penggunaan cooling tower sangat dibutuhkan untuk dapat menstabilkan temperatur air dalam kondensor maksimal hingga 60-65 oC. Perbedaan tempertur boiler, ketel dan kondensor dimana temperatur air dalam kondensor masih terlalu tinggi $(85 \mathrm{oC})$. Hal ini perlu treatment khusus untuk menjaga temperatur kondensor pada temperatur rendah agar proses perubahan fase uap ke cair dapat dikondisikan dengan baik
\end{abstract}

Kata Kunci : Boiler, Water tube, Ketel, Kondensor, Waktu Penyulingan

\begin{abstract}
etermined by the quality of the nutmeg and the use of refining process technology used. Drying techniques for raw materials and the distillation process which includes kettle, cooling system, and boiler design for refining affect the yield and quality of the essential oils produced. Boilers are made of 304 stainless steel with a diameter of $70 \mathrm{~cm}$, a length of $120 \mathrm{~cm}$, and a plate thickness of $3 \mathrm{~mm}$. Boilers are also equipped with a water tube system to accelerate water heating. Overpressure is controlled by a pressure safety valve because the boiler is designed with a pressure capacity of 3 bar. The kettle is made of 304 stainless steel which is equipped with a tiered basket to maximize circulation and steam pressure in the kettle. Condenser pipes in cooling water use aluminum pipes to maximize the condensation process. During the heating
\end{abstract}


Fitriadi, N., Pengaruh Penambahan Water Tube dan Penggunaan Air Panas Hasil ...

process the water in the water tube continues to increase in temperature up to 80 oC in the 90th minute. The temperature of the water pumped into the boiler has reached $73 \mathrm{oC}$ sourced from the condenser. In line with the increase in temperature of the water in the condenser, this results in a stable temperature when adding water to the boiler. The average temperature reduction is only $2.7 \mathrm{oC}$. The use of hot water from the condenser can increase the effectiveness of the boiler to produce steam that is transferred to the boiler. This causes the temperature in the kettle to stabilize immediately in the 90th minute with an average temperature of $110 \mathrm{oC}$. Water templates produced by the condenser survive at 84-85oC. This condition is caused by the addition of water into the condenser which is done after the water in the condenser is pumped into the boiler. In addition to being able to increase the effectiveness of boilers and boilers, the tempertur water in the condenser can also reduce the ability of the condenser pipe to change the vapor phase to liquid. The use of cooling towers is needed to be able to stabilize the water temperature in the maximum condenser up to 60-65 oC. The difference in the temperature of the boiler, boiler and condenser where the temperature of the water in the condenser is still too high $(85 \mathrm{oC})$. This needs special treatment to keep the temperature of the condenser at a low temperature so that the process of changing the vapor phase to liquid can be properly conditioned

Keywords: Boiler Water tube, Kettle, Condenser, Distillation Time

How to Cite: Fitradi, N., 2019, Pengaruh Penambahan Water Tube dan Penggunaan Air Panas Hasil Penyulingan Pada Boiler Terhadap Lama Waktu Penyulingan Minyak Pala, JMEMME (Journal of Mechanical Enggineering, Manufactures, Materials and Energy), 3(02): 123-129 


\section{PENDAHULUAN}

Indonesia merupakan negara yang kaya akan beraneka ragam tanaman yang mempunyai banyak manfaat dan mudah tumbuh. Salah satu tanaman yang banyak memberi manfaat dalam kehidupan sehari-hari adalah tanaman Pala (Myristica fragrans Houtt). Hampir semua bagian dari tanaman pala seperti daun, buah, bunga dan biji pala dapat diolah menjadi berbagai macam produk yang bernilai ekonomis. Salah satu produk unggulannya adalah minyak atsiri Pala [1] [2].

Minyak pala dapat dihasilkan dari daun, biji dan fuli buah pala. Kandungan minyak dalam daun tidak lebih dari $1,7 \%$, sedangkan fuli pala dapat menghasilkan 4-17\% minyak [3]. Produksi minyak atsiri dari buah pala dilakukan melalui proses penyulingan (distilasi). Ada empat metode penyulingan yang umum digunakan yaitu metode distilasi uap, distilasi air, distilasi uap-air, dan ekstraksi dengan menggunakan pelarut. Ditinjau dari kecepatan dan kapasitas produksi minyak, metode penyulingan yang umum digunakan untuk memperoleh minyak pala adalah metode distilasi uap [4].

Proses penyulingan dilakukan dengan menggunakan uap dari biji dan fuli yang telah masak dan kering. Distilasi uap untuk pengambilan minyak biji pala dikondisikan pada tekanan di bawah atmosferik karena biji pala memiliki komponen minyak lemak [5]. Minyak pala diperoleh setelah lemak yang terkandung di dalamnya dibuang terlebih dahulu. Penyulingan dengan tekanan tinggi dapat menyebabkan kemungkinan terikutnya minyak lemak sehingga mengurangi mutu minyak atsiri tersebut [6].

Tujuan dari penelitian ini adalah mengetahui pengaruh penambahan water tube dan penggunaan air panas hasil penyulingan pada boiler terhadap lama waktu penyulingan minyak pala.

\section{METODE PENELITIAN}

Alat penyuling minyak pala tipe water tube [7] yang dihasilkan dari penelitian ini terdiri dari beberapa komponen yaitu ketel uap, ketel suling, tangki kondensor, dan menara pendingin. Ketel Uap (Boiler) adalah wadah penampung air yang akan dipanaskan. Ketel uap ini telah dibuat dari bahan Stainless steel A304 dengan diameter $40 \mathrm{~cm}$, tinggi $70 \mathrm{~cm}$ dan tebal plat $3 \mathrm{~mm}$. Ketel uap harus dilengkapi dengan manometer dan termometer untuk mengontrol tekanan dan temperatur dalam boiler [8]. Kelebihan tekanan dikontrol dengan pressure safety valve. Boiler tersebut didesain dengan kapasitas tekanan sebesar 3 bar. Waktu yang dibutuhkan untuk mencapai tekanan sebesar 3 bar adalah 30 sampai 40 menit.

Ketel suling merupakan wadah buah pala yang menerima transfer uap dari boiler, sehingga uap membawa ekstrak buah pala bersamaan dengan uap panas. Hal yang harus diperhatikan pada saat proses penguapan adanya titik kebocoran pada ketel suling. Adanya kebocoran akan mempengaruhi uap yang dihasilkan. Setelah dilakukan uji coba dan penyempurnaan berulang kali, ketel pala yang terbuat dari bahan besi 
Fitriadi, N., Pengaruh Penambahan Water Tube dan Penggunaan Air Panas Hasil ...

stainlees steel dengan seri A304 dengan ketebalan $3 \mathrm{~mm}$ ini sudah mendekati sempurna baik titik kebocoran yang terdapat pada tutup ketel suling maupun pada pipa ke kondensor. Kapasitas efektif dari alat penyuling minyak pala sistem water tube adalah $35-50 \mathrm{~kg}$ buah pala [2].

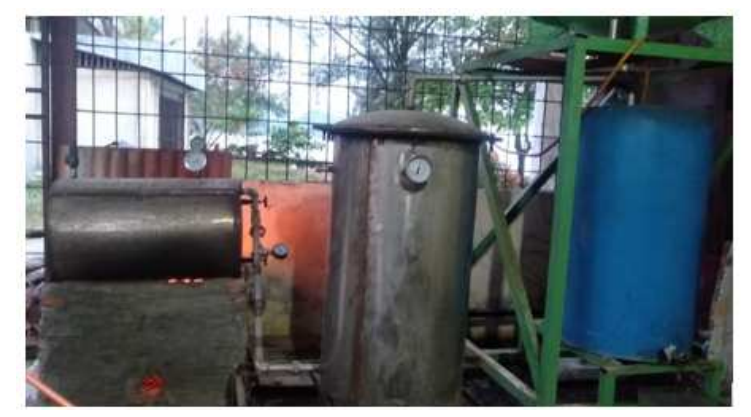

Gambar 1. Proses penyulingan pala

Tangki kondensor (warna biru), seperti yang terlihat pada Gambar 1 digunakan untuk merubah fasa uap menjadi fasa cair. Untuk memperoleh rendemen minyak yang diinginkan, kestabilan suhu air harus terus diperhatikan. Sedangkan menara pendingin (cooling tower) merupakan alat yang berfungsi untuk mensirkulasikan air untuk mengubah suhu panas yang di hasilkan oleh kondensor. Konsumsi bahan bakar dengan menggunakan kayu bakar sebanyak 20 ikat, dengan berat masingmasing $10 \mathrm{~kg}$ per ikat. Secara keseluruhan, penyulingan dengn sistem water tube ini memiliki kelebihan dibandingkan dengan alat penyulingan kompensional yang biasa digunakan oleh masyarakat di Kabupaten Aceh Selatan dalam menyuling minyak atsiri dari buah pala. Penyulingan minyak pala dengan sistem water tube dapat menghemat waktu untuk pemanasan boiler. Dengan demikian, proses penyulingan dapat dilakukan lebih cepat dari biasanya.

\section{HASIL DAN PEMBAHASAN}

Dari hasil pengujian diperoleh bahwa perbedaan yang sangat signifikan antara penggunaan air panas dalam kondensor yang dimasukkan ke dalam boiler jauh lebih efektif dalam proses penyulingan. Proses penyulingan seperti ditunjukkan pada Gambar 2 berlangsung selama 600 menit atau selama 10 jam.

Pengujian efektifitas alat penyulingan dilakukan sebanyak 2 tahap dengan perbedaan penggunaan input air ke boiler dengan temperatur normal dan menggunakan air dari dalam kondensor. Pada Gambar 2 ditunjukkan bahwa peningkatan temperatur dalam boiler terjadi pada menit ke 30 sebasar 57 oC dan terus naik pada kondisi rata-rata pada menit ke 40 sebesar 75 oC dan telah menghasilkan uap yang ditrasfer ke ketel. Pada menit ke 60 (titik hitam ke 6) temperatur maksimal yang diperoleh sebasar 83 oC, namun pada saat yang sama air dimasukkan ke dalam boiler yang mengakibatkan terjadinya penurunan temperatur hingga 68 oC (titik merah pertama). Rata-rata penurunan temperatur yang terjadi sebesar 9,95 oC. 


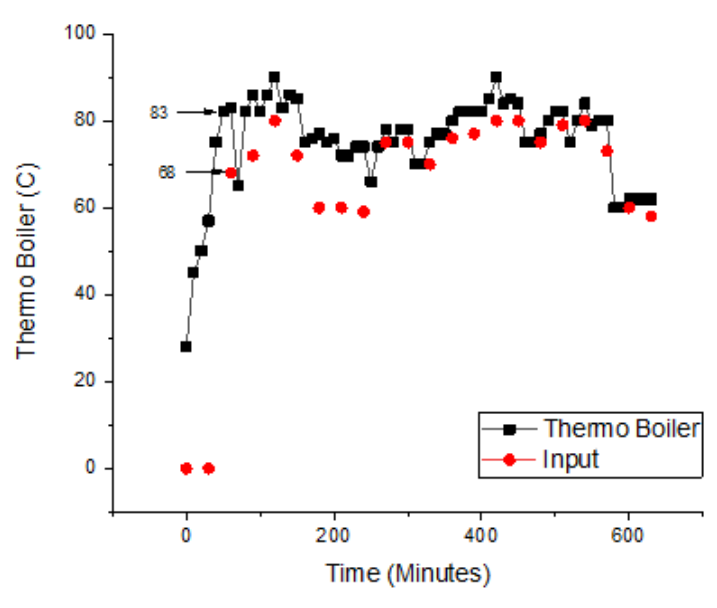

Gambar 2. Grafik temperatur boiler terhadap waktu

Penurunan temperatur ini relatif besar karena sangat mempengaruhi jumlah uap yang ditransfer ke ketel. Walaupun demikian temperatur yang tercatat pada ketel relatif stabil pada 100 oC seperti diperlihatkan pada Gambar 3.

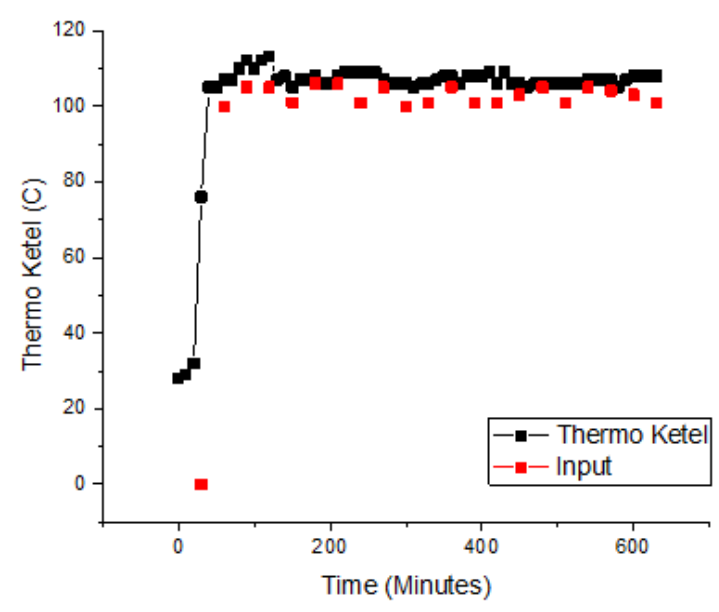

Gambar 3. Grafik temperatur ketel terhadap waktu

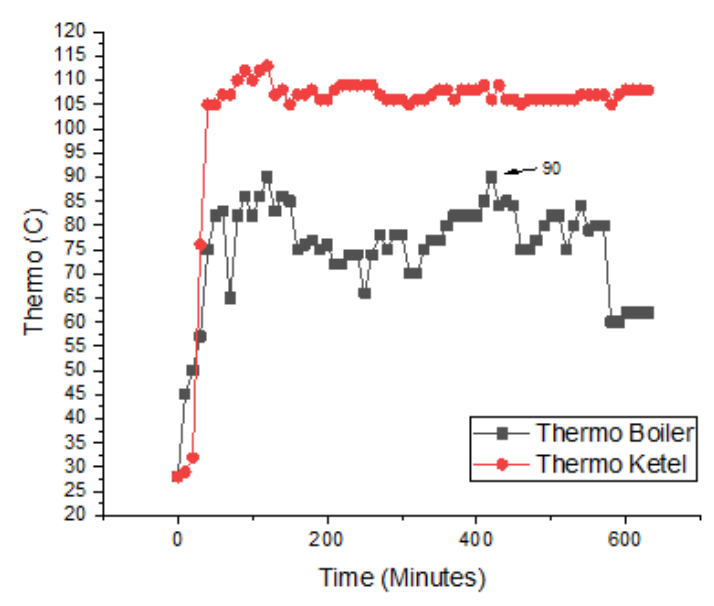

Gambar 4. Grafik temperatur ketel dan boiler terhadap waktu

Perbandingan temperatur antara boiler dan ketel pada pengujian pertama seperti ditunjukkan pada Gambar 4. Jika diperhatikan, temperatur boiler maksimal hanya mencapai 90 oC dan pada saat pengisian air penurunan maksimalnya pada 80 oC. Dengan kondisi ini, uap yang ditransfer ke ketel mampu untuk menstabilkan temperatur ketel dengan rata-rata 100 oC. Hal ini sangat dipengaruhi oleh penggunaan water tube pada boiler karena pada water tube ini air dipanaskan dan menghasilkan uap dengan temperatur stabil ke ketel.

Pengujian pada tahap kedua dilakukan dengan menggunakan air input dari kondensor. Air ini terus mengalami kenaikan temperatur karena tidak menggunakan cooling tower. Waktu proses penyulingan sama dengan pengujian tahap pertama. Pengukuran temperatur pertama dilakukan pada boiler seperti pada Gambar 5. 
Fitriadi, N., Pengaruh Penambahan Water Tube dan Penggunaan Air Panas Hasil ...

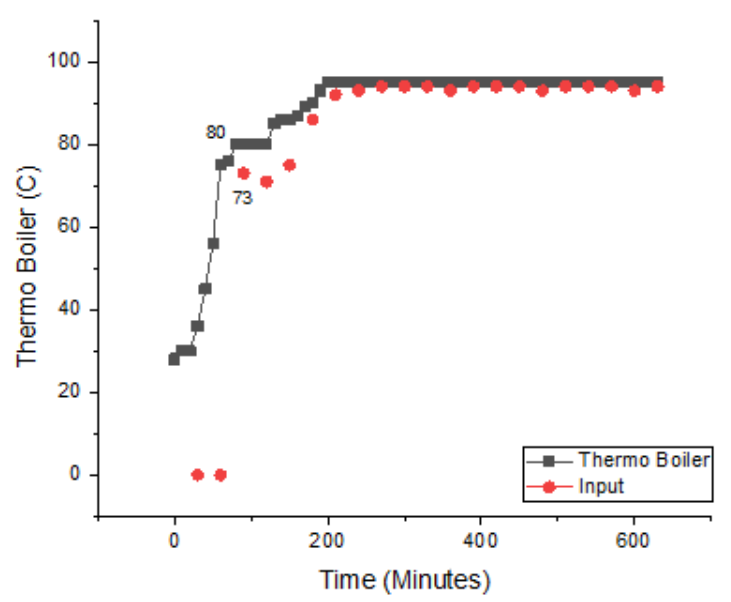

Gambar 5. Grafik temperatur boiler terhadap waktu

Selama proses pemanasan air di dalam water tube terus terjadi peningkatan temperatur hingga $80 \mathrm{oC}$ pada menit ke 90. Temperatur air yang dipompakan ke dalam boiler sudah mencapai 73 oC yang bersumber dari kondensor. Sejalan dengan peningkatan temperatur air di dalam kondensor, hal ini mengakibatkan kestabilan temperatur pada saat penambahan air dalam boiler. Rata-rata penurunan temperatur hanya $2,7 \mathrm{oC}$.

Penggunaan air panas dari kondensor pada Gambar 6 dapat meningkatkan efektifitas boiler untuk menghasilkan uap yang ditransfer ke ketel. Hal ini menyebabkan temperatur di ketel langsung stabil pada menit ke 90 dengan rata-rata temperatur sebesar 110 oC seperti diperlihatkan pada Gambar 7.

Tempertur air yang dihasilkan oleh kondensor bertahan pada 84-85 oC. Kondisi ini diakibatkan oleh penambahan air ke dalam kondensor yang dilakukan setelah air dalam kondensor tersebut dipompa ke boiler. Tempertur air dalam kondensor ini selain dapat meningkatkan efektifitas boiler dan ketel tetapi juga dapt menurunkan kemampuan pipa kondensor untuk merubah fase uap ke cair. Penggunaan cooling tower sangat dibutuhkan untuk dapat menstabilkan temperatur air dalam kondensor maksimal hingga 60-65 oC.

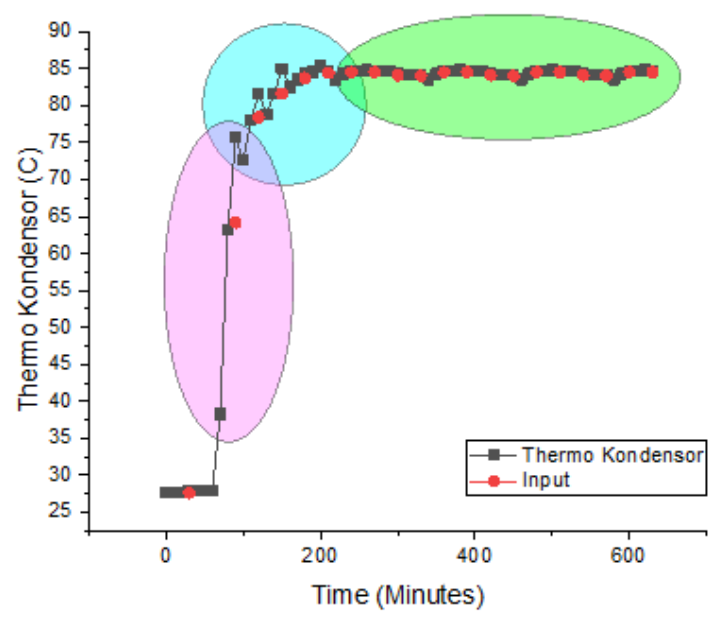

Gambar 6. Grafik temperatur kondensor terhadap waktu

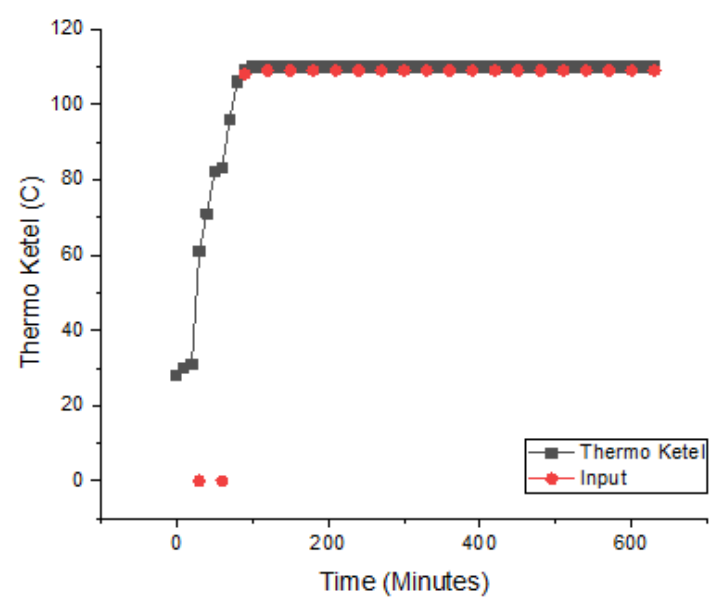

Gambar 7. Grafik temperatur ketel terhadap waktu

Perbedaan tempertur boiler, ketel dan kondensor diperlihatkan pada Gambar 8 dimana temperatur air dalam 
kondensor masih terlalu tinggi (85 oC). Seperti yang telah dijelaskan di atas bahwa temperatur kondensor harus dijaga pada temperatur rendah agar proses perubahan fase uap ke cair dapat berlangsung secara optimal.



Gambar 8. Grafik perbedaan temperatur boiler, ketel dan kondensor terhadap waktu

Sesuai dengan tujuan dari penelitian, maka dapat diketahui bahwa penambahan water tube dan penggunaan air panas hasil penyulingan pada boiler dapat mempersingkat waktu penyulingan minyak pala karena uap yang dihasilkan selalu stabil.

\section{KESIMPULAN}

Dari hasil penelitian yang telah dilakukan, dapat disimpulkan bahwa penggunaan air panas dari kondensor dapat meningkatkan efektifitas boiler untuk menghasilkan uap yang ditransfer ke ketel, penurunan temperatur dalam boiler hanya sebesar 2,9 oC. Jika air yang dipompoakan ke dalam boiler menggunakan air temperatur normal akan menurunkan temeratur air dalam boiler sebesar 9,7 oC. Dengan menggunakan sistem water tube, proses penyulingan dapat dipercepat karena temperatur di ketel lebih stabil.

\section{PENGHARGAAN}

Penulis mengucapkan terimakasih kepada Direktorat Riset dan Pengabdian Masyarakat (DRPM) Kementrian Riset Teknologi dan Pendidikan Tinggi yang telah memberikan hibah Penelitian Dosen Pemula pada tahun 2019

\section{REFERENCES}

[1] Nanan Nurdjanah, Teknologi Pengolahan Pala. BADAN PENELITIAN DAN PENGEMBANGAN PERTANIAN BALAI BESAR PENELITIAN DAN PENGEMBANGAN PASCAPANEN PERTANIAN, 2007.

[2] N. Fitriadi and E. Saputra, "Rancang Bangun Ketel Pala dengan Sistem Water Tube," J. Inotera, vol. 2, no. 1, pp. 42-48, 2017.

[3] B. Jakarta, "BSN (Badan Standarsasi Nasional)," in SNI o6-2388-1998,Minyak pala, Jakarta, 2006.

[4] S. S. G and I. Telussa, "Karakteristik Minyak Atsiri dari Daging Buah Pala Melalui Beberapa Teknologi Proses," J. Teknol. Has. Pertan., vol. 4, no. 2, pp. 1-9, 2011.

[5] N. Hidayati, H. Ilmawati, and E. Sara, "PENYULINGAN MINYAK BIJI PALA: PENGARUH UKURAN BAHAN, WAKTU DAN TEKANAN PENYULINGAN TERHADAP KUALITAS DAN RENDEMEN MINYAK," in Prosiding Simposium Nasional Rekayasa Aplikasi Perancangan dan Industri, 2015.

[6] C. A. Duarte, E. Espejo, and J. C. Martinez, "Failure analysis of the wall tubes of a water-tube boiler," Eng. Fail. Anal., vol. 79, pp. 704-713, 2017.

[7] S. Wang, D. Yang, Y. Zhao, and M. Qu, "Heat transfer characteristics of spiral water wall tube in a $1000 \mathrm{MW}$ ultrasupercritical boiler with wide operating load mode," Appl. Therm. Eng., vol. 130, pp. 501-514, 2018.

[8] W. Beyne, S. Lecompte, B. Ameel, D. Daenens, M. Van Belleghem, and M. De Paepe, "Dynamic and steady state performance model of fire tube boilers with different turn boxes," Appl. Therm. Eng., vol. 149, pp. 1454-1462, 2019. 